\title{
O PENSAMENTO LIBERTINO EM GAMIANI OU DUAS NOITES DE ORGIA, DE ALFRED DE MUSSET
}

\author{
LIBERTINE THOUGHT IN GAMIANI OR TWO NIGHTS OF EXCESS, BY ALFRED \\ DE MUSSET
}

Ederson Vertuan

Universidade Estadual de Londrina

RESUMO: O propósito desta investigação é identificar a influência do pensamento das escolas libertinas dos séculos XVII e XVIII no romance erótico Gamiani ou duas noites de orgia, de Alfred de Musset, e determinar se o romance se filia a uma ou mais dessas escolas.

PALAVRAS-CHAVE: Alfred de Musset; Gamiani; Libertinagem de espírito; Libertinagem de costumes.

ABSTRACT: The purpose of this investigation is to identify which libertine ideas are present in the erotic novel Gamiani or Two Nights of Excess, by Alfred de Musset, and determine if the novel adheres to one or more schools of libertine thought of the seventeenth and eighteenth centuries.

KEYWORDS: Alfred de Musset; Gamiani; Libertinage d'esprit; Libertinage de moeurs. 


\section{Revista do SELL}

v. $4, n^{\circ} .2$

ISSN: $1983-3873$

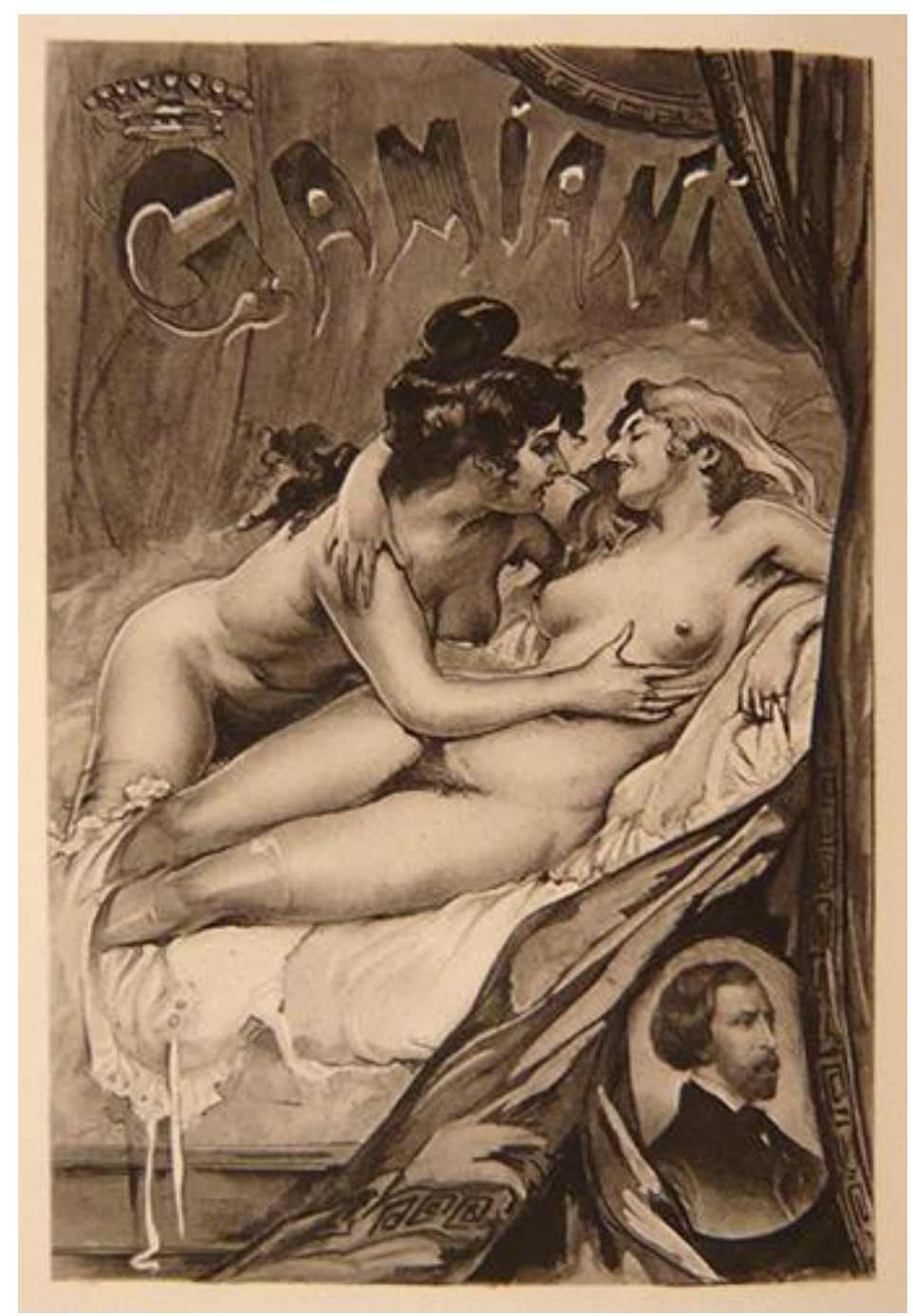

Figura 1: Heliogravura de Paul Avril (1849-1928) para Gamiani ou deux nuits d'exces, par Alcide, baron de M..., edição de $1905 . \quad$ Disponível em: <http://www.livresanciens.eu/shop/anciens/19202.html >.

Em 1833, Alfred de Musset redige e publica, anonimamente, um curto romance com o propósito de se vingar de sua então-companheira George Sand, que o havia traído durante uma viagem à Itália. O tema do lesbianismo abordado na história até mesmo condizia com a biografia da escritora, que se vestia como homem e cuja "má" reputação era assegurada por cartas pessoais, rumores e declarações de contemporâneos seus: Vigny "temia que ela roubasse sua amante e o barão Dudevant, com quem havia casado e abandonado, não tinha melhor opinião a seu respeito"1.

\footnotetext{
${ }^{1}$ In effetti, costei era stata più volte accusata di lesbismo (de Vigny temeva seriamente che gli portasse via l'amante, ed il barone Dudevant, da lei sposato e abbandonato, non ne aveva miglior opinione). Todas as traduções livres são do autor desse estudo. A "amante" em questão era a atriz Marie Dorval. Existe a hipótese de que Sand e Dorval tenham tido um caso.
} 


\section{Revista do SELL}

v. $4, n^{\circ} .2$

ISSN: $1983-3873$

Gamiani ou duas noites de orgia $(1833)^{2}$ - eis o título do romance ${ }^{3}$ - é um livro tão curioso quanto o silêncio crítico a que permanece submetido. Parece haver uma quase completa falta de documentos de rigor científico com relação a ele tanto em língua francesa quanto inglesa, italiana e portuguesa. Além da polêmica afinidade do romance com a biografia de Musset e de Sand - considerada a primeira escritora francesa de renome -, o livro foi um bestseller da literatura erótica no século XIX. Gamiani foi a "obra licenciosa mais lida e mais reeditada de todo [o período]. Louis Perceau, em 1930, chegou a catalogar mais de 40 edições, sem contar as traduções" (ARCHET, 2010, p. 1) ) $^{4}$

Não foram poucas as adaptações de Gamiani, seja para cinema ou teatro, dentre as quais se destacam Gamiani (1981) e Countess Gamiani (1997) - filmes dirigidos por Ismael González e Franco Lo Cascio, respectivamente - e as adaptações teatrais de Riccardo Reim, "que, por duas vezes, encenou Gamiani, em 1984 e em 2002, com grande sucesso de público e crítica" (GAMIANI... 2010a).

O silêncio crítico que envolve o livro ainda é curioso porque, apesar de sua grande importância para o gênero da literatura erótica, a discussão acerca de suas fontes e de sua autoria permanece não resolvida: a anedota exposta no primeiro parágrafo deste trabalho não passa de uma entre muitas versões sobre a origem da obra. A esse respeito, o jornalista italiano Giovanni Dall'Orto cita uma observação de Mirella di Maio, que diz ser impossível atribuir a obra ao casal Musset-Sand: "A obra sai, de fato, antes do rompimento entre os dois, em 1833" (MAIO apud DALL'ORTO, 2005) ${ }^{6}$. Além disso, Straight (2003), na introdução a dados sobre a primeira edição (Paris, 1833), informa que apenas a primeira parte do romance tem sido atribuída a Sand e Musset, não havendo, contudo, indícios que possam comprovar essa hipótese.

Muitos, também, são os que defendem a autenticidade da autoria de Musset. É o caso de Poulet-Malassis, em uma edição francesa, publicada, em 1997, pela editora Dominique Leroy. Em nota bio-bibliográfica, Poulet-Malassis (1997, p. 6), editor da

\footnotetext{
$\overline{2}$ Doravante, apenas Gamiani.

${ }^{3}$ Título original: Gamiani, ou deux nuits d'excès (Inglês: Gamiani, or Two Nights of Excess; Italiano: Gamiani - due notti di eccessi).

${ }^{4}$ [...] l'ouvrage licencieux le plus lu et le plus souvent réimprimé de tout de XIX ${ }^{e}$ siècle. Louis Perceau, en 1930, en recensait déjà une quarantaine d'éditions, sans compter les traductions.

${ }^{5}$ (che per due volte ha portato in scena Gamiani - nel 1984 e nel 2002 - con grande successo di pubblico e critica). Uma terceira adaptação foi dirigida por Antonio Salines em seis datas de Agosto de 2010, a maioria na Província de Trento, Itália. Encenada pela Companhia de Teatro Belli, as apresentações foram bastante divulgadas e tiveram o apoio do Município de Trento.

${ }^{6}$ Itálicos do autor. Em defesa de sua afirmação, o jornalista aponta um catálogo online em que se encontra uma edição anterior, publicada em Londres no ano de 1780. Tal lista está disponível em $<$ http://www.eroticabibliophile.com/books gamiani.php $>$.
} 


\section{Revista do SELL}

v. $4, n^{\circ} .2$

ISSN: $1983-3873$

primeira edição de 1833, afirma: "Existem provas de que Alfred de Musset seja o autor desse romance". E a nota continua: "Não há como negar que o círculo dos escritores românticos sabia perfeitamente que Musset havia sido o autor desse texto" (p. 6). Por sua vez, o prefácio à terceira edição (Amsterdã, 1864), reproduzido nessa mesma publicação, baseia-se nas similitudes entre a personagem Gamiani e a escritora George Sand, apelidada, em sua época, de "coronela das tríbades" (p. 13), para se posicionar a favor da atribuição do livro ao casal Musset-Sand.

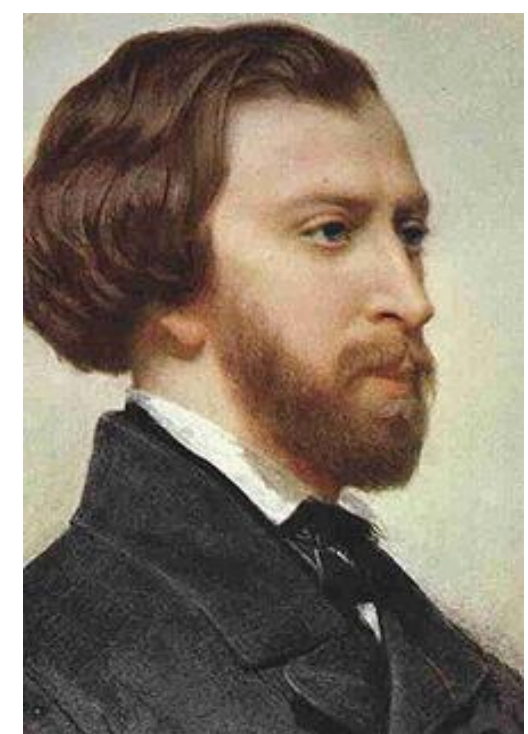

Figura 2: Retrato a óleo de Alfred de Musset (1854), Charles Landelle (1812-1908).

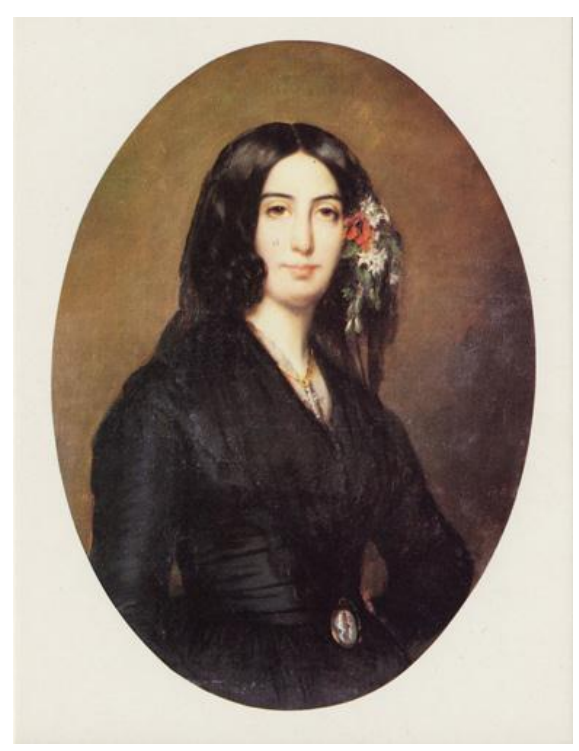

Figura 3: George Sand aos 33 anos. Retrato de George Sand (1838), Auguste Charpentier (1813-1880), Musée de la Vie romantique, Paris.

Quando se trata de fontes, a mesma indefinição persiste. Além da suspeita da participação de Sand na criação do livro (que também não é comprovada), há a hipótese de que Musset tenha escrito o romance para se vingar não da escritora, mas de uma mulher chamada Cristina di Belgiojoso (GAMIANI..., 2010b). Existe, ainda, outra versão segundo a qual o romance se basearia nas aventuras devassas do próprio Musset, sozinho e ao lado de Sand, bem como na morte de uma célebre cantora chamada Malibran (ARCHET, 2010, p. 1).

Desde sua publicação, Gamiani se consolidou como obra de expressiva importância dentro do gênero da literatura erótica do século XIX e ainda desperta o interesse de diretores, platéias e cinéfilos. No que diz respeito ao campo da literatura, o 


\section{Revista do SELL}

v. $4, n^{\circ} .2$

ISSN: $1983-3873$

romance é importante porque sintetiza pressupostos de várias escolas de libertinagem difundidos desde os primeiros livres-pensadores do século XVII aos libertinos de costumes do século XVIII. O propósito da investigação proposta, portanto, é identificar quais ideias libertinas estão presentes nesse romance erótico e determinar se o livro se filia a uma ou mais escolas de pensamento libertino dos séculos XVII e XVIII.

Alcides é um jovem que se diz intrigado com a misteriosa personalidade da bela e rica condessa Gamiani, por quem nutre um ódio secreto. Em um baile na casa da condessa, Alcides se surpreende com o comentário de um dos convivas, que, ao se referir a ela, exclama: "Ora! É uma tríbade!" (MUSSET, 1998, p.10). O jovem, confuso, se diz dividido entre desejo e repulsão pela condessa. No entanto, Alcides decide se vingar de Gamiani e se esconde em seu quarto para desmascará-la. Depois do baile, o jovem, oculto em um compartimento de vestir, observa a entrada de Gamiani acompanhada de uma jovem convidada, Fanny, que, surpreendida por uma tempestade, fora obrigada a passar a noite em casa de sua anfitriã. Gamiani inicia um jogo de sedução que desconcerta a jovem. Alcides, antes impassível, aturde-se com cena de sedução que assiste. A interação entre as duas mulheres alcança tamanha intensidade passional que Alcides, incapaz de sofrear seus ímpetos eróticos, abandona o plano de desforra e salta sobre o corpo de Fanny. Uma série de prazeres se inicia entre os três, entrecortada por histórias autobiográficas acerca de suas respectivas iniciações eróticas. 


\section{Revista do SELL}

v. $4, n^{\circ} .2$

ISSN: $1983-3873$

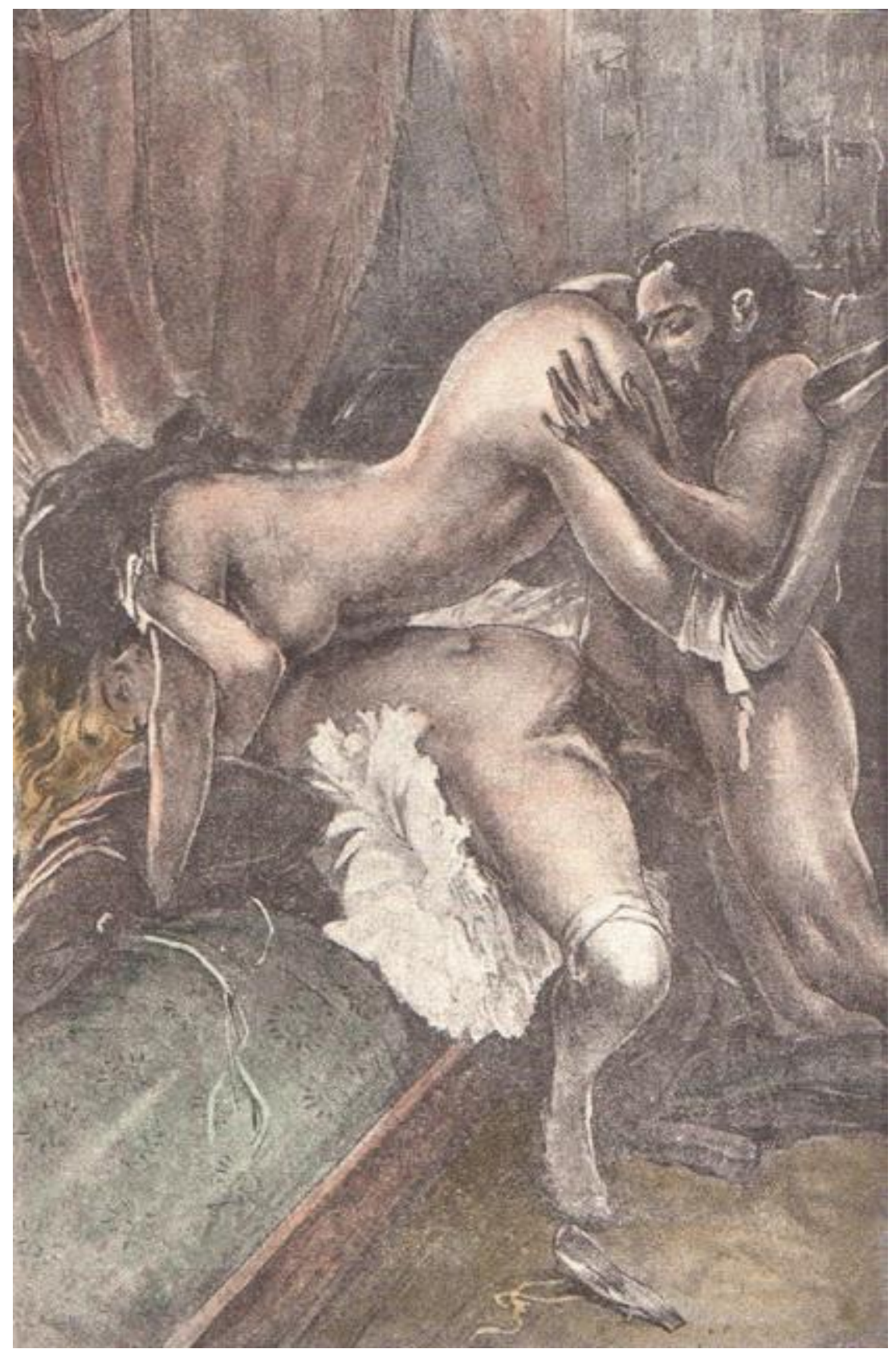

Figura 4: Heliogravura de Paul Avril (1849-1928) para Gamiani ou deux nuits d'exces, par Alcide, baron de M..., edição de 1931. Disponível em: <http://livres-anciensrares.blogspot.com.br/2012/09/gamiani-ou-deux-nuits-dexcesillustre.html >. 


\section{Revista do SELL}

v. $4, n^{\circ} .2$

ISSN: $1983-3873$

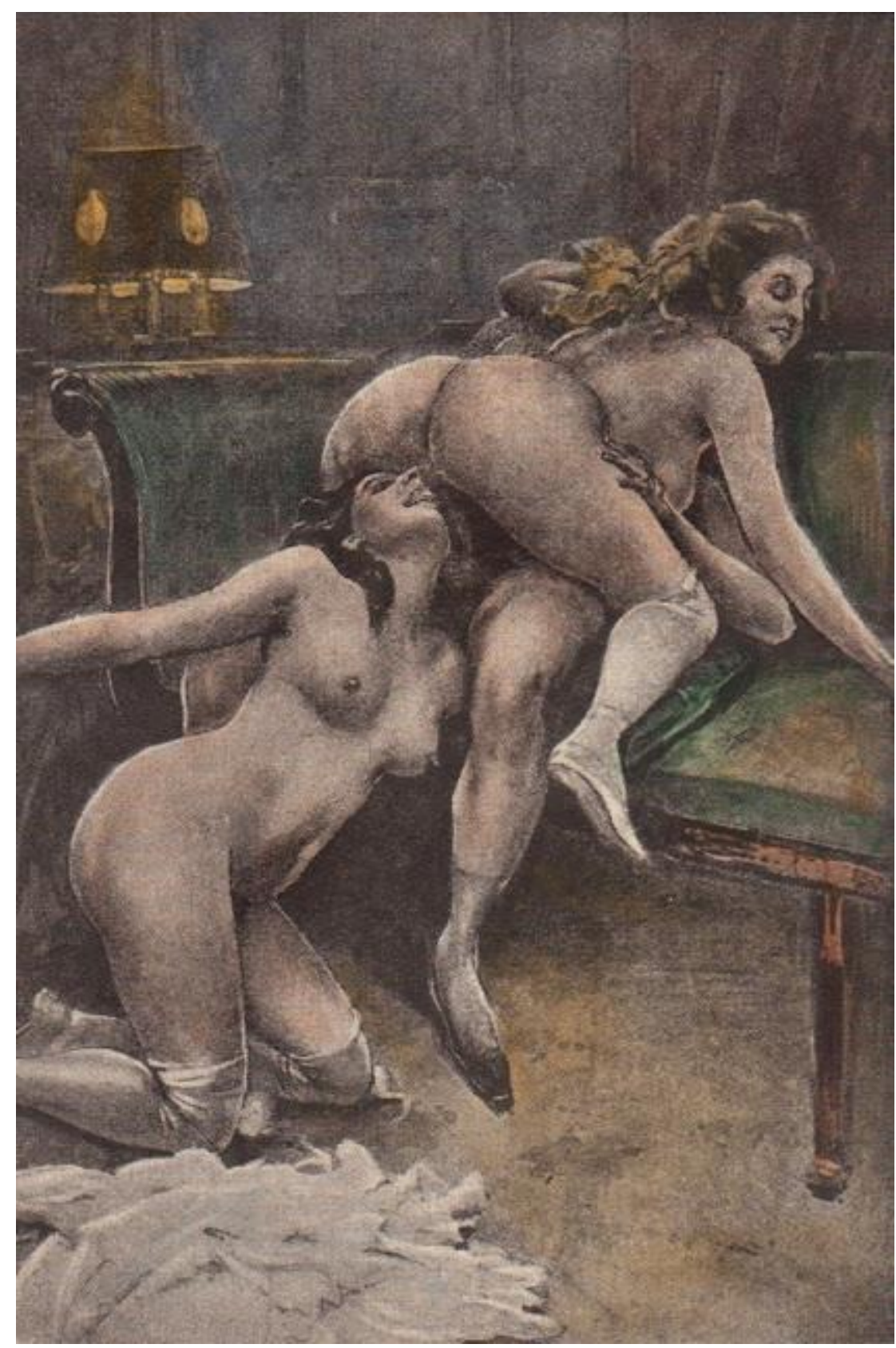

Figura 5: Heliogravura de Paul Avril (1849-1928) para Gamiani ou deux nuits d'exces, par Alcide, baron de M..., edição de 1931. Disponível em: <http://livres-anciens-rares.blogspot.com.br/2012/09/gamiani-ou-deuxnuits-dexces-illustre.html>.

A segunda parte do livro se passa pouco tempo depois da primeira noite na casa de Gamiani. Alcides e Fanny estão em um relacionamento; mas, o jovem desconfia que Fanny esteja cultivando um desejo secreto por Gamiani. Para testar a fidelidade da amada, Alcides usa do mesmo expediente da primeira noite e, a pretexto de uma ausência qualquer, esconde-se em um compartimento oculto com vista para o interior do quarto de Fanny. Para a surpresa dele e da própria jovem, Gamiani entra no quarto, disfarçada de criada e a seduz. Ela, relutante, acaba assumindo seu amor secreto pela 


\section{Revista do SELL}

v. $4, n^{\circ} .2$

ISSN: $1983-3873$

condessa. As duas mulheres se entregam a momentos de intensa paixão, entre os quais Gamiani narra alguns episódios de sua vida. A condessa fala sobre o tempo em que fora abusada por sua tia, sobre a fuga para o convento (onde é exposta a desvarios sexuais de toda ordem), a mudança de vida e o amor não carnal vivenciado ao lado do jovem Edward, bem como sobre a decepção do amor espiritual que se desfaz ante as tentações do desejo, o retorno à vida de prazeres e o rompimento de relações com homens.

O desfecho do romance ocorre quando Gamiani bebe um licor misterioso e o serve a Fanny dizendo se tratar de uma bebida revigorante. Pouco depois de beber o líquido, Fanny sente fortes dores e percebe que havia sido envenenada. Ela morre logo em seguida, em meio a gestos indiferentes de Gamiani, que continua a se estimular, eroticamente, sobre o cadáver. Abalado com o que vê, Alcides arromba a porta do aposento na esperança de ajudar às duas mulheres. Antes de morrer sobre o cadáver de Fanny, Gamiani explica a Alcides que sua intenção era descobrir a existência de alguma experiência sensual nos estertores da morte.

Apesar de abordar temas como violência e exploração sexual, pedofilia, zoofilia, orgias entre religiosas, voyerismo e necrofilia - todos, elementos que tem levado alguns críticos a questionarem a "seriedade" da obra -, o romance promove um debate significativo no que se refere ao pensamento libertino. 


\section{Revista do SELL}

v. $4, n^{\circ} .2$

ISSN: $1983-3873$

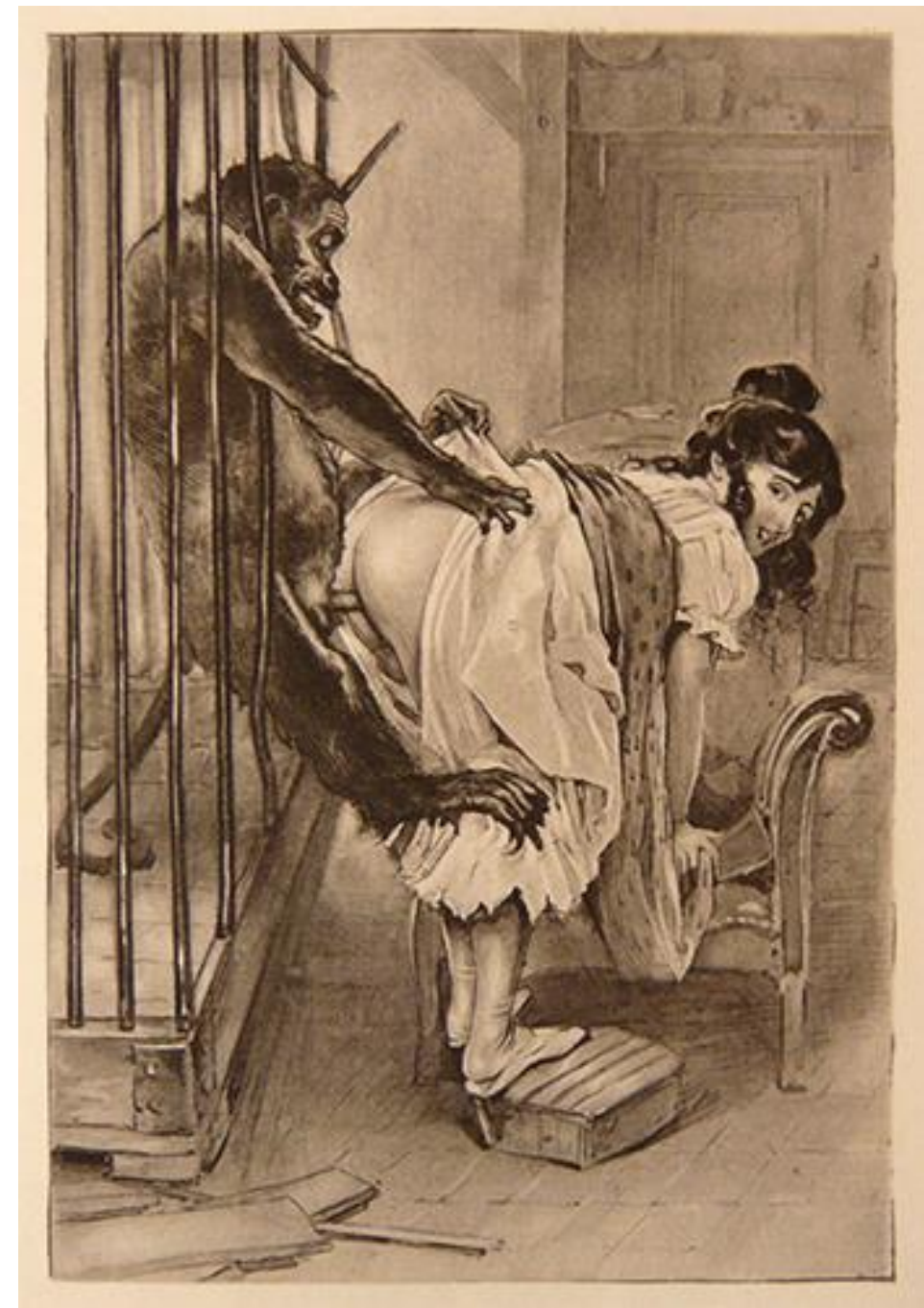

Figura 6: Heliogravura de Paul Avril (1849-1928) para Gamiani ou deux nuits d'exces, par Alcide, baron de M..., edição de $1905 . \quad$ Disponível em: <http://www.livresanciens.eu/shop/anciens/19202.html>.

\section{OS PRIMEIROS LIBERTINOS: A LIBERTINAGEM DE ESPÍRITO}

A história do pensamento libertino ${ }^{7}$ é marcada por diferentes escolas de pensamento cujas primeiras ideias datam do século XVII. Cada escola possui suas convicções particulares e diferem entre si com relação a vários temas, em especial, quanto à religião. As primeiras ideias ligadas ao pensamento libertino surgem nos séculos XVI e XVII. São denominados de rebeldes ou libertinos os seguidores mais extremos de correntes como o laicismo pagão de Maquiavel ou da conduta moral insubmissa dos

\footnotetext{
${ }^{7}$ De acordo com Moraes (2006), a acepção moderna da palavra libertin, originária no século XVIII, evoca tudo o que é desenfreado com relação à moralidade entre os gêneros masculino e feminino.
} 


\section{Revista do SELL \\ v. $4, n^{\circ} .2$ \\ ISSN: $1983-3873$}

personagens de Boccaccio. Autores como Cyrano de Bergerac, Theophile de Viau e SainArmand são os primeiros dessa linhagem de pensamento, na passagem do século XVI para o XVII, e é durante esse último século que o pensamento libertino desponta na cultura francesa, não sendo "poucos os autores a ele vinculados ou por ele influenciados" (MORAES, 2006, p. 80).

O pensamento libertino do século XVII tem como uma constante quase absoluta a condição de inimigo da religião. Mas não totalmente, visto que o pensamento libertino desse período não segue uma única linha de comportamento ou de posição frente ao tema religioso. Existiram pensadores que, por exemplo, passaram a vida inteira na descrença, ou que, tendo sido descrentes, se converteram ao cristianismo, como Cyrano de Bergerac e Theophile de Viau. Até mesmo o deísmo foi seguido por intelectuais como Saint-Évremont.

De modo geral, pode-se dizer que a libertinagem do século $\mathrm{XVII}$ era, essencialmente, oposta às verdades da religião e à autoridade dos que detinham o poder. Os libertinos desse período foram, em suma, rebeldes políticos e religiosos. De acordo com Pintard (2000), por exemplo, havia quem fosse descrente das profecias e das revelações, como Belurgey; outros duvidavam das ações demoníacas (Hullon, Bourdelaut, Mézeray) e da bruxaria (Marolles, Monconys, Boulliau, Gabriel Naudé); e outros, ainda, descriam das possessões e dos exorcistas, como Quillet, Boulliau, Guy Patin, Grammont e Monconys.

O sistema de pensamento dos libertinos iniciado pelos chamados livrespensadores do século XVII tem como embasamentos principais de seu sistema algumas concepções de "fontes clássicas" (MORAES, 2006, p. 82) como o epicurismo e o estoicismo, que pressupõem uma postura de indiferença à morte e que conferem "à vida - e seus prazeres - um sentido maior" (p. 84). Bastante influentes são as traduções de Lucrécio no que diz respeito ao panteísmo epicurista, bem como o livro De la sagese, de Charron, que inspira a "atitude de indiferença característica do comportamento estóico" (p. 83). De acordo com Moraes (2006), o sistema de pensamento do filósofo Gassendi ${ }^{8}$ baseia-se nas teorias de Epicuro e inspira discípulos como Cyrano de Bergerac e Molière. Essas fontes clássicas e de tradição hedonista ${ }^{9}$ serão retomadas do Renascimento para

\footnotetext{
${ }^{8}$ Pierre Gassendi (1592-1655).

${ }^{9}$ Concepção filosófica segundo a qual a busca do prazer e a supressão da dor são a únicas finalidades da vida.
} 


\section{Revista do SELL}

v. $4, n^{\circ} .2$

ISSN: $1983-3873$

se estenderem até o século XVIII, século em que a libertinagem de espírito e, sobretudo, a libertinagem de costumes, irão se delinear.

Um dos mais influentes representantes da libertinagem de espírito é d'Holbach ${ }^{10}$, ateísta convicto, defensor do livre-pensamento e adversário feroz da religião. A libertinagem de espírito foi uma libertinagem de ideias, difundidas por d'Holbach em seus livros e discutidas entre quatro paredes, apenas entre amigos próximos. No primeiro capítulo de seu trabalho mais famoso, o O Sistema da Natureza (1770), d'Holbach repete, continuamente, a ideia central de que o homem se equivoca quando adere a sistemas de pensamento imaginários:

É pelos sentidos que o homem se liga à Natureza. É pelos sentidos que ele deve penetrar seus segredos. É pelos sentidos que ele deve experimentar suas leis. Mas quando ele falha em adquirir experiência ou abandona tal caminho, [...] sua imaginação o conduz ao erro. ${ }^{11}$ (D'HOLBACH, 2001, p. 12)

Ou, como diz em outro momento: "[é] à física e à experiência que o homem deve recorrer em todas as suas investigações" (D’HOLBACH apud MORAES, 2006, p. 89). As ideias de d'Holbach estão muito presentes no cenário intelectual do inicio do século XVIII, especialmente sua posição em favor da razão e do livre- pensamento como arma contra a tirania política e religiosa: "o padre e o tirano têm a mesma política e os mesmos interesses: só precisam, um e outro, de sujeitos imbecis e submissos” (p. 90).

\footnotetext{
${ }^{10}$ Paul-Henri Thiry, Baron d'Holbach (1723-1789).

${ }^{11}$ It is by his senses man is bound to this universal Nature; it is by his senses he must penetrate her secrets; it is from his senses he must draw experience of her laws. Whenever, therefore, he either fails to acquire experience or quits its path, he stumbles into an abyss, his imagination leads him astray.
} 


\section{Revista do SELL}

v. $4, n^{\circ} .2$

ISSN: $1983-3873$

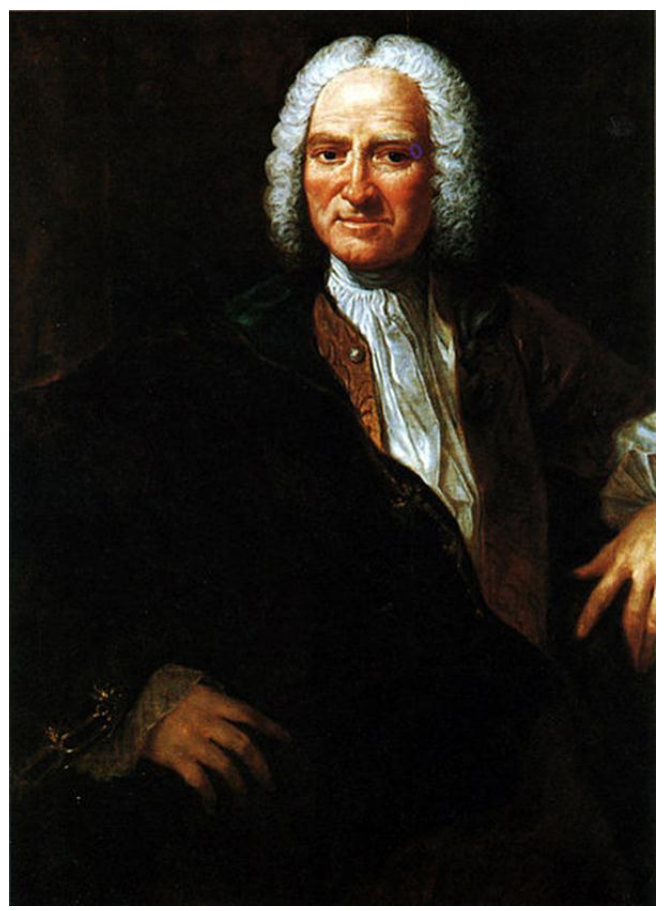

Figura 7: Paul-Henri Thiry, Baron d'Holbach (1723 - 1789) foi autor, filósofo, enciclopedista e figura de destaque do lluminismo Francês.

\section{A LIBERTINAGEM DE COSTUMES}

É com a libertinagem de costumes que as ideias dos libertinos de espirito são aplicadas na prática. As primeiras escolas de livres pensadores do século XVII fazem de muitos intelectuais do século seguinte seus "herdeiros diretos" (MORAES, 2006, p. 92). No século XVIII, o banditismo da nobreza ${ }^{12}$ será "substituído pelo crime de libertinagem, relacionado à vida galante, ao refinamento dos prazeres, à insaciável busca de novas experiências" (p. 92) e os libertinos de costumes vão se consolidar como um grupo de "características particulares: desafio à moral e à religião, desprezo pelos preconceitos vulgares e prática de atos cruéis, principalmente a violência sexual" (p. 92). É nesse momento que a simples rebelião aos ensinamentos religiosos e à "autoridade do poder" (p. 82) das primeiras escolas libertinas (século XVII) é substituída pela revolta contra a moral e transformada em um "ateísmo radical" (p. 82) no século XVIII.

\footnotetext{
${ }_{12}$ O banditismo da nobreza dos séculos XVI e XVII foi, em parte, derivado das práticas de caça. Em 1723, o duque de Charolais (1700-1760) matou um homem por puro divertimento.
} 


\section{Revista do SELL}

v. $4, n^{\circ} .2$

ISSN: $1983-3873$

Os libertinos de costumes eram indivíduos que se davam a toda sorte de práticas antirreligiosas, como bruxaria, assassinatos, promiscuidade sexual, xingamentos, insultos a celebrações religiosas, incestos, bebedeira e ostentação do comportamento libertino, orgias, farras com prostitutas, atentado ao celibato religioso, ostentação de relações ilícitas, ressentimento contra familiares, embriaguez constante, temperamento violento, práticas amorosas cruéis e assassínios brutais.

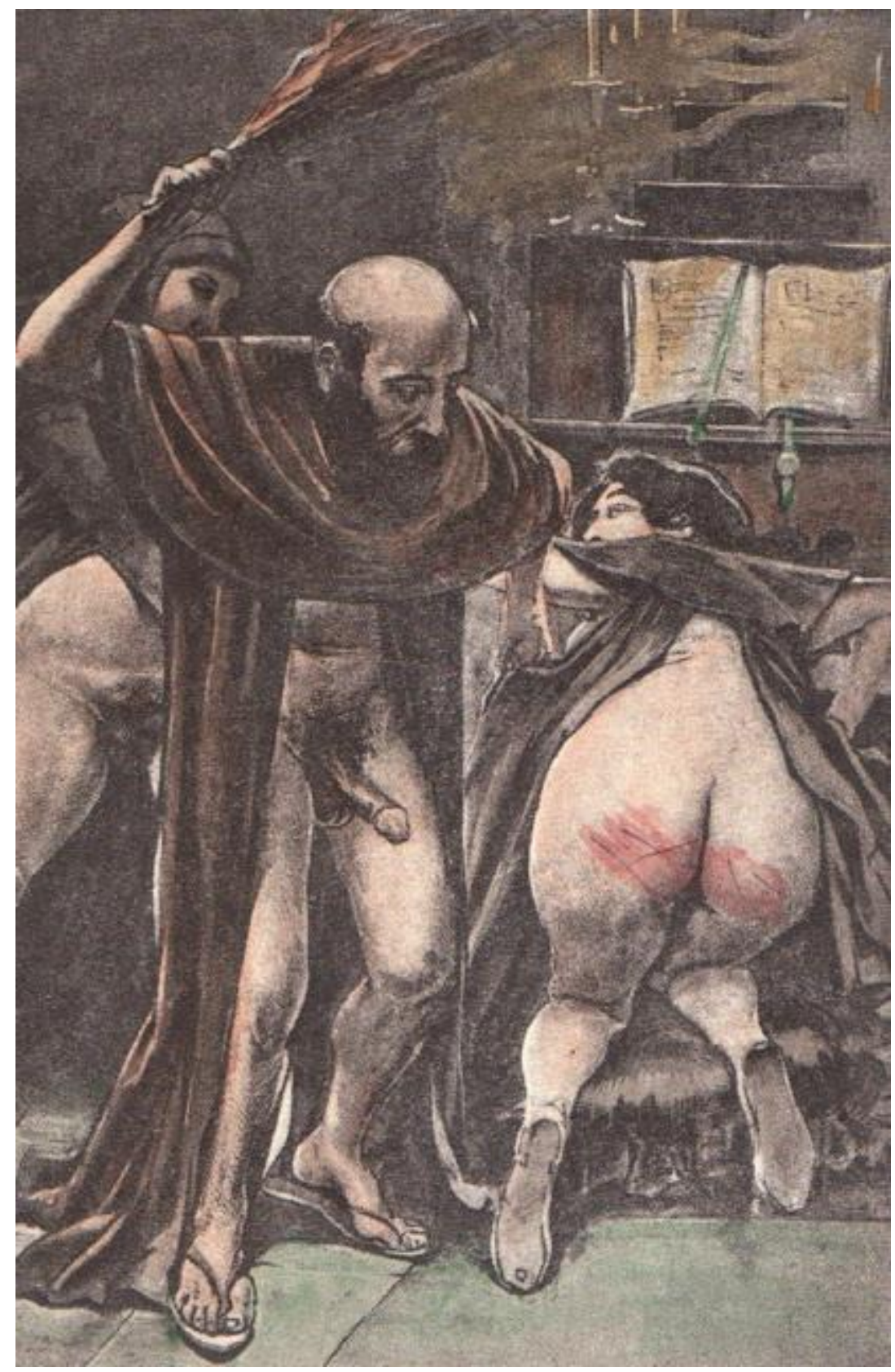

Figura 8: Heliogravura de Paul Avril (1849-1928) para Gamiani ou deux nuits d'exces, par Alcide, baron de M..., edição de 1931. Disponível em: $<$ http://livres-anciensrares.blogspot.com.br/2012/09/gamiani-ou-deux-nuits-dexcesillustre.html>. 


\section{Revista do SELL}

v. $4, n^{\circ} .2$

ISSN: $1983-3873$

É em tal contexto comportamental que surgem, no século XVIII, inúmeras associações de libertinos que, inspirados no modelo das sociedades secretas, congregam-se cada qual em torno de uma prática libertina particular. As diferentes posturas apresentadas por essas associações inspiraram verdadeiras discussões entre escritores libertinos acerca do tema sentimental. Alguns, por exemplo, queriam unir a paixão da carne ao sentimento e justificar a prática sexual a partir do amor, posição ilustrada em obras como Teresa filosofa (1748), do marquês d'Argens, e Fanny Hill ou Memórias de uma mulher de Prazer (1748), de John Cleland, cujo desfecho é harmonioso e deixa sua protagonista sem qualquer necessidade de se afastar da sexualidade para amar, nem de "rejeitar o amor para realizar os prazeres da carne" (MORAES, 2006, p, 98).

Outros intelectuais, pelo contrário, defendiam à ideia de que a sedução do personagem conquistador, de caráter donjuanesco, sagaz e racionalista, era apenas possível a partir da rejeição ao sentimento. Esta é a linha de pensamento seguida por muitos personagens libertinos criados pelo famoso Marques de Sade e para os quais "é quando colocado à prova do prazer que o sentimento desmorona por completo" (MORAES, 2006, p, 99), segundo afirma a personagem Mme. de Saint-Ange, de $A$ Filosofia na Alcova (1795).

O livro Gamiani realiza um debate entre estas duas linhas de pensamento com relação ao sentimento, ora abordando a ideia de que é possível unir amor espiritual e amor físico, ora aderindo à ideia de que o prazer físico destrói o sentimento.

\section{GAMIANI E O PENSAMENTO LIBERTINO}

Assim que foge do convento e se refugia em Florença, Gamiani conhece um jovem chamado Edward, que a faz despertar "aos tons puros, encantadores, de um amor nobre e elevado" (MUSSET, 1998, p. 81) e com quem experimenta "esses desejos vagos, inefáveis, que geram a felicidade e poetizam a vida..." (p. 81). O livro Gamiani começa a abordar a questão da união entre amor e desejo carnal através das cenas de amor virtuoso entre Edward e Gamiani e que ela experimenta após ter, até então, se dedicado à busca pelos prazeres dos sentidos: "Até lá, só o meu corpo se agitara, vivera; minha alma 


\section{Revista do SELL}

v. $4, n^{\circ} .2$

ISSN: $1983-3873$

ainda dormia" (p. 81). Mas o amor idílico dos dois só dura enquanto há ausência de contato físico. Segundo Gamiani, Edward "não teve mais força o bastante para combater os sentidos. Surpreendeu-me um dia adormecida e me possuiu" (p. 82). A esse episódio, segue-se o fim da relação entre ambos - "o encanto se quebrara" (p. 82) —, pois, para Gamiani, Edward, agora, não passava de "um homem de carne e osso" (p. 82).

No entanto, o livro não permanece, por todo o tempo, "filiado" a uma única noção acerca da questão sentimento-prazer: a de que amor e prazer jamais se conciliam. A união entre amor e prática erótica se torna possível com o relacionamento entre Gamiani e Fanny: "[Fanny:] Eu fiquei feliz, bem feliz!". "[Gamiani:] Eu também [...] e senti uma felicidade que me era desconhecida. Era a alma e os sentidos reunidos em teus lábios...!" (MUSSET, 1998, p. 59). O relacionamento entre Gamiani e Fanny baseia-se na experiência simultânea dos dois tipos de amor, o erótico e o sentimental, e que, para Gamiani, só é possível através da relação com outra mulher. O elemento masculino (Edward) é o responsável pela destruição da pureza do sentimento, pois, em sua fraqueza, é ele quem cede às tentações do prazer. Para Gamiani, o "pecado" é trazido não pela mulher; mas, pelo homem, numa espécie de inversão do mito de Adão e Eva que irá motivar, em definitivo, o seu afastamento de relações com homens. 


\section{Revista do SELL}

v. $4, n^{\circ} .2$

ISSN: $1983-3873$

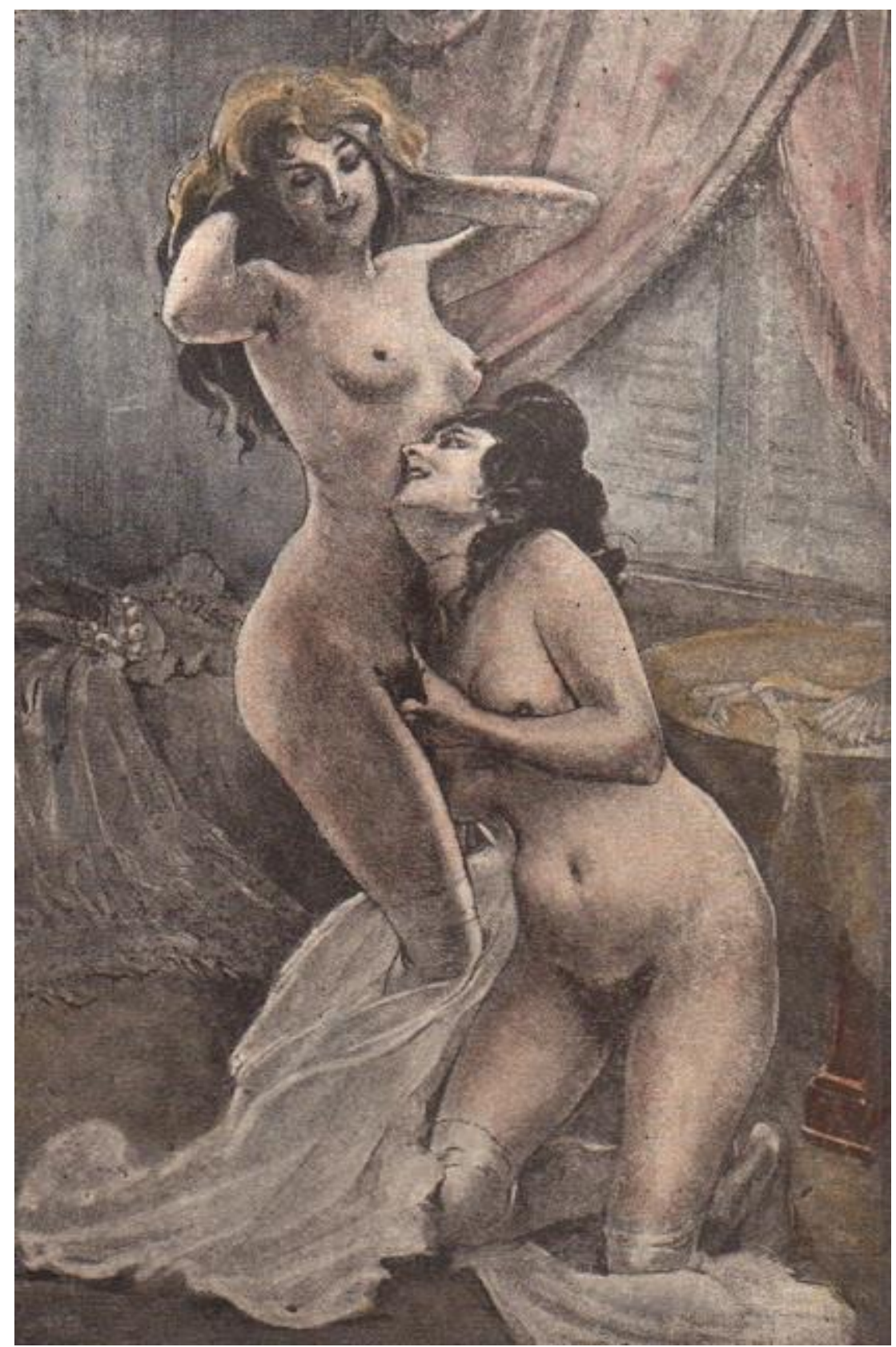

Figura 9: Heliogravura de Paul Avril (1849-1928) para Gamiani ou deux nuits d'exces, par Alcide, baron de M..., edição de 1931. Disponível em: <http://livres-anciens-rares.blogspot.com.br/2012/09/gamiani-ou-deuxnuits-dexces-illustre.html>.

O episódio entre Gamiani e Edward aborda a não conciliação entre a "paixão da carne e a paixão do coração" (MORAES, 2006, p. 98), postura para a qual é imperativo "rejeitar o amor para realizar os prazeres da carne" (p. 98). Em Gamiani, o amor e incapaz de escapar ileso das provações do prazer.

É a essa convicção que a maior parte do romance se mantém filiada. Gamiani é uma libertina que despreza os "gozos metafísicos" (MORAES, 2006, p. 99) e "só reconhece [...] a insaciabilidade da carne" (p. 99). Apesar da união entre prazer e 


\section{Revista do SELL}

v. $4, n^{\circ} .2$

ISSN: $1983-3873$

sentimento se concretizar nos momentos finais da obra, o desfecho do livro ilustra a defesa da ideia de que a busca pelo prazer acaba predominando sobre o sentimento, não importando o quão elevado ele possa parecer. Gamiani trai sua amante: a experiência lasciva a interessa mais do que o sentimento. A embriaguez dos sentidos, o excesso e a crueldade $^{13}$ triunfam sobre ele:

É horrível! Exclamei alucinado.

\section{ALCIDES}

GAMIANI

Sim! Mas conheci todos os êxtases dos sentidos. Louco, agora compreendes. Restava-me saber se, na tortura do veneno, se, na agonia de uma mulher misturada à minha própria agonia, havia uma sensualidade possível! Ela é atroz! Compreendes! Morro no furor do prazer, no furor da dor!... Não posso mais!... Oh!...

Com esse grito prolongado, emanado do fundo de seu ser, a horrível fúria cai morta sobre o cadáver de Fanny! (MUSSET, 1998, p. 90)

O desfecho do romance constitui-se também no desenlace do conflito interior de Gamiani, que, até aquele momento, não havia se decidido sobre a qual dos dois aderir definitivamente - se ao prazer, se ao sentimento. A condessa opta, no fim, pelo primeiro: comparada à "horrível fúria" (MUSSET, 1998, p. 90) Alecto, a "implacável”, seu desejo sensual é inapaziguável. Para Moraes (2006 p. 99), "às diferentes correntes dos clubes secretos [de libertinos] correspondem as distintas posições acerca do amor expressas nesse gênero literário [...]". A complexidade da discussão presente em Gamiani acerca do prazer e do sentimento faz da obra uma espécie de síntese das duas posturas do pensamento libertino com relação ao sentimento e ao prazer.

O desfecho da história "combina a petit mort" com a própria morte" (ARCHET, 2010) ${ }^{15}$. Gamiani deseja conhecer o prazer de morrer. Ou, antes, saber da - hipotética - existência de algum prazer na morte. É a experiência insana (extrema) dos sentidos que traz à Gamiani o conhecimento que ela almeja: "louco, agora compreendes"16 (MUSSET, 1998, p. 90). Gamiani entrega sua própria vida pelo conhecimento, que só pode ser acessado por meio da experiência e da razão. A condessa põe em prática, até às últimas consequências, a convicção de que "é pelos sentidos que [o homem] deve

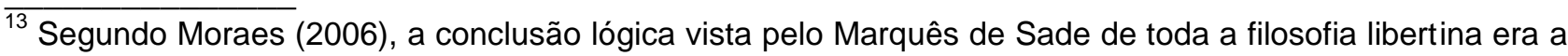
crueldade.

${ }_{14}^{14}$ Pequena morte: expressão idiomática e metafórica através da qual os franceses se referem ao orgasmo.

${ }_{16}^{15}$ [The culmination of the story] [...] combines the little death and death itself:

${ }^{16}$ Eco da apologia da "experiência" feita por d'Holbach. Quanto mais intensa é a experiência, maior o conhecimento.
} 


\section{Revista do SELL}

v. $4, n^{\circ} .2$

ISSN: $1983-3873$

penetrar [os] segredos [da Natureza]" (D'HOLBACH, 2001, p. 12). Gamiani é uma livrepensadora e, como tal, representa aqueles que, no passado, arriscaram suas vidas em nome do conhecimento científico, sob o olhar ameaçador da autoridade dogmática da religião.

A impassibilidade de Gamiani à dor e à morte são marcas de seu estoicismo libertino. Sua disposição em morrer pelo prazer, além disso, marca a importância que ela empresta à experiência lúbrica dos sentidos. Gamiani, enquanto personagem libertina, não só experimenta "todos" os prazeres sensuais, conforme ela própria afirma: ela também vivencia quase todas as formas de libertinagem, desde a libertinagem de costumes das cenas antirreligiosas no convento até à libertinagem dos prazeres do espírito que vivencia na relação sentimental com Edward.

Gamiani consiste em uma personagem movida pelo desejo de conhecer o máximo do prazer que o mundo físico pode proporcionar. A simples ideia de uma personagem que chega a dar a vida em nome da experiência dos sentidos e do conhecimento é, por si, um fato que eleva Gamiani de uma narrativa erótica, aparentemente, sem importância a uma obra de peso no que respeita à literatura e à filosofia libertinas.

\section{REFERÊNCIAS}

ARCHET, Anne. Gamiani ou Deux nuits d'excès. 2010. Disponível em: $<$ http://archet.net//'ete-c'est-l'enfer/gamiani-ou-deux-nuits-d'exces/>. Acesso em: 21 Dez. 2010 COGGIOLA, Massimiliano Mocchia di. Gamiani, ovvero due notti di eccessi. 2007. Disponível em: <www.arterotica.eu/2576-romanzo-gamiani-alcide.htm>. Acesso em 2 Jan. 2011.

DALL'ORTO, Giovanni. Gamiani [1833]. Lesbismo e perversioni varie per stuzzicare i maschi etero. 2005. Disponível em:

$<$ http://www.culturagay.it/cg/recensione.php?id=11066>. Acesso em: 29 Jul 2011. D'HOLBACH, Baron. The System of Nature. Volume 1. 2001. Disponível em $<$ http://socserv.mcmaster.ca/ econ/ugcm/3\|l3/holbach/volume1.pdf >. Acesso em: 25 Jul. 2011.

GAMIANI... 2010a. Disponível em: <http://www.comune.trento.it/Citta/Vivi-la-citta/Eventidi-interesse/Gamiani-ovvero-una-notte-di-eccessi2>. Acesso em: 25 Dez. 2010.

GAMIANI... 2010b. Disponível em: <http://www.libroco.it/cgibin/dettaglio.cgi/codiceweb=715241819857110/9788860631695/Gamiani//ConiglioEditore.html>. Acesso em: 13 Dez. 2010.

MUSSET, Alfred de. Gamiani ou duas noites de orgia. São Paulo: Imaginário, 1998. . Gamiani ou deux nuits d'exces: L'enfer de la bibliothèque nationale de France.

Paris: Dominique Leroy, 1997, p. 6. 


\section{Revista do SELL}

v. $4, n^{\circ} .2$

ISSN: $1983-3873$

MORAES, Eliane Robert. Um libertino no salão dos filósofos. In: MORAES, Eliane Robert. Lições de Sade: ensaios sobre a imaginação libertina. São Paulo, Iluminuras, 2006, pp. 77-102.

PINTARD, René. Le Libertinage Erudit dans la première moitié du XVIleme siècle. Genéve: Editions Slatkine, 2000.

STRAIGHT, Sheryl. Gamiani. 2003. Disponível em:

<http://www.eroticabibliophile.com/books gamiani.php>. Acesso em: 3 Jan. 2011. 